\title{
Determination of Soil Cadmium Threshold for Potato
}

\author{
Wei Li, Xue He, Jie Zhang and Ke Liu* \\ College of Agriculture, Guizhou University, Guiyang, China
}

In this study, pot experiments were conducted to investigate the characteristics of $\mathrm{Cd}$ transfer to potato tubers from two types of soil. The results showed that the Log-normal and Burr III functions can be used to determine the sensitivity of different potato varieties to $\mathrm{Cd}$ as well as the soil $\mathrm{Cd}$ threshold. With regard to the prediction accuracy, the root mean squared error (RMSE) values for the total $\mathrm{Cd}$ biaoaccumulation factor $\left(\mathrm{BAF}_{\text {total }}\right)$ calculated with both functions were smaller than those for exogenous $\mathrm{Cd}$ biaoaccumulation (BAF add) in acidic and alkaline soils, indicating that $\mathrm{BAF}_{\text {total }}$ is more appropriate for the calculation of the soil $\mathrm{Cd}$ threshold. The average $\mathrm{Cd}$ threshold values in acidic soil calculated with the Log-normal and Burr III functions were 0.411 and $0.461 \mathrm{mg} \mathrm{kg}^{-1}$, and the average values in alkaline soil were 0.716 and 0.888 , respectively. The Log-normal function can also be

OPEN ACCESS

Edited by:

Zhi Wang,

Innovation Academy for Precision

Measurement Science and

Technology (CAS), China

Reviewed by:

Shuying $L i$,

Zhejiang University, China

Molla Fenite Mengist,

North Carolina State University,

United States

*Correspondence:

Ke Liu

gzdxlk@126.com

Specialty section:

This article was submitted to

Toxicology, Pollution and the

Environment,

a section of the journal

Frontiers in Environmental Science

Received: 03 November 2021

Accepted: 10 February 2022

Published: 23 February 2022

Citation:

Li W, He X, Zhang J and Liu K (2022) Determination of Soil Cadmium Threshold for Potato.

Front. Environ. Sci. 10:808362. doi: $10.3389 /$ fenvs.2022.808362 applied to fit the sensitivity distributions of different species for the development of appropriate soil $\mathrm{Cd}$ threshold values for conservation purposes.

Keywords: cd, potato, bioaccumulation, food safety, soil threshold

\section{INTRODUCTION}

Cadmium (Cd) is a toxic heavy metal that is harmful to plants, microorganisms and humans (Zhong, et al., 2015). The evaluation of soil Cd levels and Cd transfer from the soil to plants is therefore a critical issue. Potato is the fourth most important crop in China, behind wheat, rice and corn. The ecology of Karst areas is fragile and human activities are more likely to cause soil Cd pollution in these areas. Therefore, it is necessary to pay more attention to Cd transfer from the soil to crops in Karst areas (Zhang, et al., 2020).

The Cd content in different organs generally increases in the order of leaves $>$ stem/root $>$ tuber (Chen, et al., 2014). The Cd content in the tuber is less than that in other organs and most of the $\mathrm{Cd}$ is retained by other organs (Ye, et al., 2020). Soil properties such as $\mathrm{pH}$ or organic matter $(\mathrm{OM})$ markedly influence the distribution of metals between the phytoavailable and non-phytoavailable sections of a plant (Pinto, et al., 2015); (Hough, et al., 2004). Other metal ions can also affect plant absorption of $\mathrm{Cd}$ from the soil; for instance, correlation analysis of different potato varieties showed a strong positive relation between the bioaccumulation of $\mathrm{Cd}$ and the presence of zinc ( $\mathrm{Zn}$ ), copper (Cu) or manganese (Mn) (Ashrafzadeh, et al., 2017). The plant species also affect soil Cd uptake. For example, the tomato genotype affects the nutritional value, fruit quality, yield, etc, and Cd-tolerant cultivars were found to accumulate more Cd than sensitive cultivars (Carvalho, et al., 2018). The results of these studies confirmed that $\mathrm{Cd}$ uptake by plants is influenced by various factors including the soil properties and crop varieties. Biaoaccumulation factor (BAF) is used to study the transfer of a pollutant from the soil to plants and to calculate the threshold value for the pollutant in the soil to ensure food safety. A prediction model for $\mathrm{Pb}$ transfer to wheat from 17 soil types with different $\mathrm{Pb}$ levels in China was fitted using the BAF and soil properties to determine the soil 
$\mathrm{Pb}$ threshold (Liu, et al., 2016). Some scholars developed and compared regression models based on BAF for the uptake of Cd by potatoes through field investigations (Novotna, et al., 2015).

The cumulative probability distribution method have been used to evaluate the risk of pollutants in humans and are helpful to establish the soil threshold for heavy metals as well as for soil screening. The species sensitivity distribution (SSD) is a typical cumulative probability distribution that reflects the differences in the sensitivity of different species to the same pollutant (Liu, et al., 2015). Environmental toxicity data for pollutants such as the concentration necessary to achieve $50 \%$ of the maximal effect $\left(\mathrm{EC}_{50}\right)$, no observed effect concentration (NOEC) and BAF for a limited number of species obtained through biological toxicity tests are sampled based on the SSD. Establishing a threshold that covers the fifth percentile of the SSD protects the majority of the species in an ecosystem (van der Hoeven, 2001). This strategy is applied more frequently to water environments; for example, the SSD for nine compounds indicates that crustaceans are the most sensitive species to anticancer drugs in aquatic ecosystems (Li D et al., 2021). Furthermore, it has been increasingly applied to soil environments in recent years. A soil-plant transfer model was applied to Cd data for 183 soil-plant pairs to fit the SSD and 5 grades of Cd sensitivity were obtained based on the Cd-BAF (Li, et al., 2019). Many function models are available for SSD fitting, including the Burr III, Log-normal, Log-logistic and Gamma functions. The Gaussian distribution function was used to determine the cumulative probability distribution for vegetables and the soil $\mathrm{Cd}$ threshold in the Hunan Province of southern China as well as to implement a reasonable soil Cd risk assessment strategy for the locality (Yang et al., 2016a). The potential health risk to humans from $\mathrm{Cd}$ exposure was evaluated using the target hazard quotient (THQ) and the probability distribution of THQ for 324 vegetable samples in Shandong, Jiangsu, Yunnan Province in China was identified with the Lognormal function (Hu, et al., 2018). The Cd toxicity threshold for paddy soil was determined based on the variation of BAF in various rice cultivars using SSD fitted with the Burr III function (Song, et al., 2015). The appropriate model depends on the specific situation in terms of the polluted species and the regulation of the environment.

In the present study, we aimed to: 1) explore the transfer of $\mathrm{Cd}$ from two types of soil with different $\mathrm{pH}$ values to potato tubers of different cultivars; 2) compare the fit of SSD curves using the Lognormal and Burr III functions for different potato cultivars in the two soil types; and 3) obtain a soil threshold value for the safe production of potato using different calculation methods for BAF.

\section{MATERIALS AND METHODS}

\section{Pot Experiments}

Soil was collected from two Karst geological regions in China, specifically from Weining and Guiyang cities in Guizhou Province. Soil samples were collected from the surface of a field $(0-20 \mathrm{~cm})$ in these regions, air dried and passed through a $2 \mathrm{~mm}$ sieve to remove large pieces of gravel prior to the pot experiments. The base $\mathrm{Cd}$ concentrations were 0.61 and $0.37 \mathrm{mg} \mathrm{kg}^{-1}$ for the Weining (yellow) and Guiyang (calcareous) soil, respectively. The two soils are the main soil types in Guizhou province. Soil properties were determined using standard methods. Soil $\mathrm{pH}$ was determined using a glass electrode with a soil:water ratio of 1:2.5 $\left(\mathrm{g} \mathrm{ml}^{-1}\right)$. The $\mathrm{pH}$ values for the Weining and Guiyang soil were 4.8 and 7.8. The measured OM values were 24.5 and $48.5 \mathrm{~g} \mathrm{~kg}^{-1}$, respectively, using the potassium dichromate oxidation method. Ten commercial potato varieties commonly grown in the local area, namely Eeshu 5 (E5), Lishu 15 (L15), Qianyu 8 (QY8), Qingshu 9 (QS9), Weiyu 5 (W5), Lishu 13 (L13), Hongbaoshi (HBS), Heimeiren (HMR), ChuangyuA5e (CA5e) and Weiyu 7 (W7), were used in the experiments.

The potato varieties were planted in the two soil types in the way of pot experiment (greenhouse). Six kilograms of soil was placed in a plastic pot to ensure the normal growth of the potatoes. Exogenous $\mathrm{Cd}$ in solution $\left(3 \mathrm{CdSO}_{4} 8 \mathrm{H}_{2} \mathrm{O}\right)$ was added to the soil and mixed uniformly. Two treatments were applied, with three replicates for each pot. The control treatment (CK) lacked additional $\mathrm{Cd}$, and $0.9 \mathrm{~m} \mathrm{~kg}^{-1} \mathrm{Cd}$ was mixed with the two soil types for the $\mathrm{Cd}$ treatment. The amount of $\mathrm{Cd}$ added was based on the risk value for Chinese $\mathrm{Cd}$ soil contamination in agricultural land ( $0.3 \mathrm{mg} \mathrm{kg}^{-1}$ for soil $\mathrm{pH} \leqq 7.5,0.6 \mathrm{mg} \mathrm{kg}^{-1}$ for soil $\mathrm{pH}>7.5$ ). Additionally, $0.15 \mathrm{~g} \mathrm{~kg}^{-1} \mathrm{~N} \quad\left(\mathrm{CO}\left(\mathrm{NH}_{2}\right)_{2}\right), 0.05 \mathrm{~g} \mathrm{~kg}^{-1} \mathrm{P}(\mathrm{Ca}$ $\left.\left(\mathrm{H}_{2} \mathrm{PO}_{4}\right)_{2}\right)$ and $0.1 \mathrm{~g} \mathrm{~kg}^{-1} \mathrm{~K}\left(\mathrm{~K}_{2} \mathrm{SO}_{4}\right)$ were added to each pot as the base fertilizer. The treated soil was left to equilibrate for 40 days to allow the behavior of Cd ions in the soil to stabilize. Potatoes with similar sizes and weights were selected for planting in the pot experiments. The potatoes were watered with deionized water to ensure that the Cd absorbed by the plants came from the soil. The soil moisture content was maintained at about $70 \%$ of the water holding capacity.

\section{Detection of Cd in Soil and Plants}

After passing the soil through a 100 mesh sieve, $0.1 \mathrm{~g}$ was weighed (accurate to 0.0001) and transferred to a polytetrafluoroethylene (PTFE) tank. Afterward, $3 \mathrm{ml}$ nitric acid, $1 \mathrm{ml}$ hydrochloric acid and $1 \mathrm{ml}$ hydrofluoric acid were added and the capped tank was placed in a matched steel pipe before digesting for $20 \mathrm{~h}$ at $180^{\circ} \mathrm{C}$ on an electric heating plate. Perchloric acid $(1 \mathrm{ml})$ was added as the acid driver. After digestion of the soil sample, the digestion solution was transferred to a $50 \mathrm{ml}$ volumetric flask and a constant volume was maintained with ultrapure water. Finally, $10 \mathrm{ml}$ of the supernatant from the digested sample solution was collected and the $\mathrm{Cd}$ concentration was measured using inductively coupled plasma mass spectrometry (ICP-MS; Thermo Fisher Scientific, Waltham, MA, United Sates, x2). The basic test conditions was injection speed: $0.8 \mathrm{ml} \mathrm{min}^{-1}$;

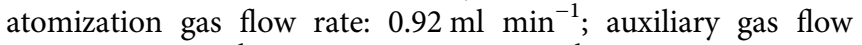
rate: $0.7 \mathrm{ml} \mathrm{min}^{-1}$; cooling gas: $13 \mathrm{~L} \mathrm{~min}^{-1}$; the detection limit of the instrument is less than $1 \mathrm{ppb}$.

Potato tubers were collected at maturity and washed three times successively with tap water and purified water to remove soil particles from the surface. The potato tubers were placed in a 

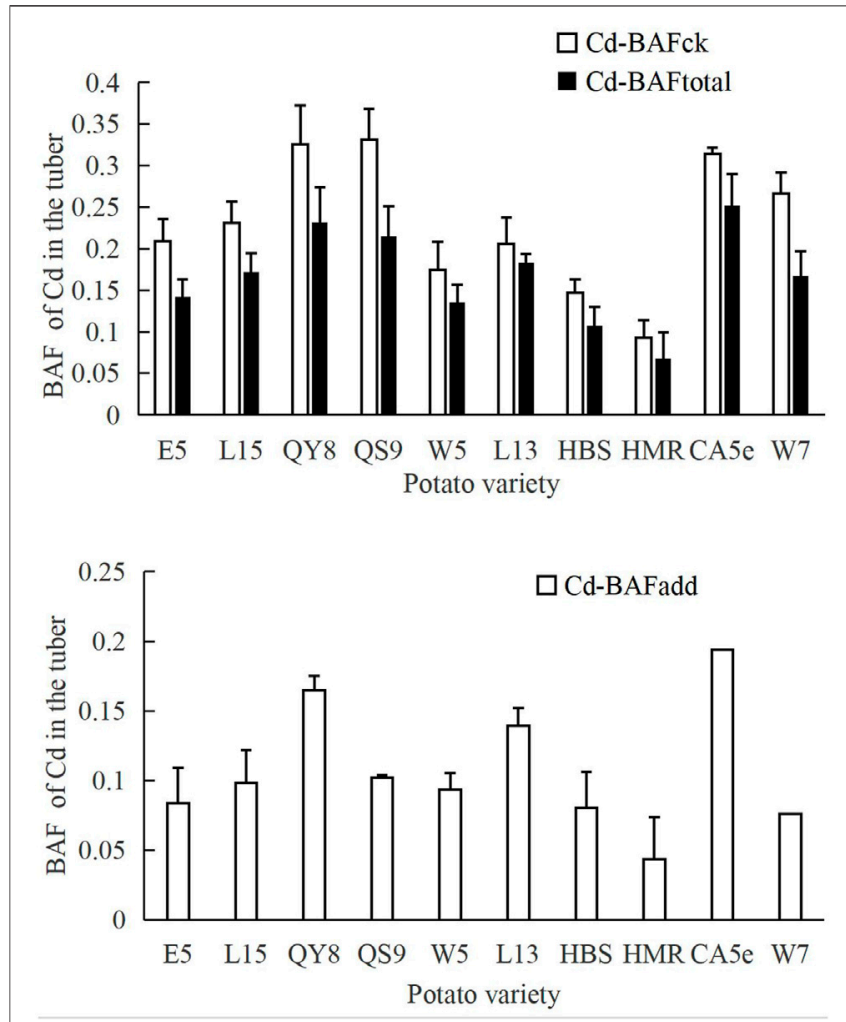

FIGURE 1| $\mathrm{BAF}_{\mathrm{ck}}, \mathrm{BAF}_{\text {total }}$ and $\mathrm{BAF}_{\text {add }}$ for different potato varieties in Weining soil.

$105^{\circ} \mathrm{C}$ electric oven for $15 \mathrm{~min}$ to remove green sections and then dried to a constant weight at $75^{\circ} \mathrm{C}$. The plant samples were ground and stored for determination of the Cd content. We weighed $0.2 \mathrm{~g}$ (accurate to 0.0001 ) of edible plant samples into a PTFE tank, then added $5 \mathrm{ml}$ nitric acid and two to three drops of hydrofluoric acid for $12 \mathrm{~h}$ for pre-digestion. The initial digestion solution was heated to $160^{\circ} \mathrm{C}$ and digested for $8 \mathrm{~h}$ to remove OM. After cooling, a constant volume of $50 \mathrm{ml}$ was maintained. The determination method for the $\mathrm{Cd}$ content in the plants was the same as that for the soil. For quality control, all the acid reagents used were of high grade purity. The glassware and PTFE tube used for digestion were soaked in $25 \%$ nitric acid solution for $12 \mathrm{~h}$ before use. The soil reference material GSS-5 and plant reference material GBW10021 were adopted for quality control.

\section{Calculation Method for BAF}

BAF represents the ratio of the heavy metal concentration in plants to the heavy metal concentration in the soil environment. The BAF for the CK treatment $\left(\mathrm{BAF}_{\mathrm{ck}}\right)$ was calculated using the equation:

$$
\mathrm{BAF}_{\mathrm{ck}}=\mathrm{C}_{\mathrm{CK}-\text { plant }} / \mathrm{C}_{\mathrm{CK}-\text { soil }}
$$

Where, $\mathrm{C}_{\mathrm{CK} \text {-plant }}$ and $\mathrm{C}_{\mathrm{CK} \text {-soil }}$ are the heavy metal concentrations in the plants and soil for the CK treatment, respectively.
The BAF for total $\mathrm{Cd}\left(\mathrm{BAF}_{\text {total }}\right)$ was calculated with the equation:

$$
\mathrm{BAF}_{\text {total }}=\mathrm{C}_{\text {plant }} / \mathrm{C}_{\text {soil }}
$$

Where, $\mathrm{C}_{\text {plant }}$ is the concentration of heavy metals in the plants and $\mathrm{C}_{\text {soil }}$ is the concentration of heavy metals in the soil for the $\mathrm{Cd}$ treatments.

Some scholars (Ding, et al., 2013) proposed a BAF calculation method for exogenous pollutants that only considers the effects of exogenous pollutants on plants. The BAF for exogenous Cd $\left(\mathrm{BAF}_{\mathrm{add}}\right)$ was calculated with the equation:

$$
\text { BAF }_{\text {add }}=\left(\mathrm{C}_{\text {plant }}-\mathrm{C}_{\mathrm{CK}-\text { plant }}\right) /\left(\mathrm{C}_{\text {soil }}-\mathrm{C}_{\mathrm{CK} \text {-soil }}\right)
$$

Where, $\mathrm{C}_{\text {plant }}$ and $\mathrm{C}_{\text {soil }}$ are the concentrations of heavy metals in the plants and soil for the Cd treatments, respectively.

\section{RESULTS AND DISCUSSION}

\section{BAF for Cd in Two Soil Types}

The variability of BAF is important for the assessment of $\mathrm{Cd}$ exposure for plants in contaminated soil and represents the current contamination situation (Augustsson, et al., 2015). As seen in Figure 1, the total Cd-BAF for tubers grown in Weining soil varied between 0.09 (HMR) - 0.33 (QS9) for $\mathrm{BAF}_{\mathrm{ck}}$ and 0.07 (HMR) - 0.25 (CA5e) for $\mathrm{BAF}_{\text {total }}$. The average $\mathrm{BAF}_{\mathrm{ck}}$ and $\mathrm{BAF}_{\text {total }}$ values for the 10 potato varieties evaluated in this study were 0.23 and 0.17 , respectively. Twenty-one potato samples were collected from a field in the Czech Republic and the average BAF was 0.34 , which was greater than the values obtained in the current study because of differences in the soil properties (Novotna, et al., 2015). The $\mathrm{BAF}_{\mathrm{ck}}$ for each potato variety was slightly higher than the corresponding BAF values for the $\mathrm{Cd}$ treatments. In contrast, the $\mathrm{BAF}_{\mathrm{ck}}$ for carrot in 21 soil types from China was less than the $\mathrm{BAF}_{\text {total }}$ for the Cd treatment (soil spiked with $0.6 \mathrm{mg} \mathrm{kg}^{-1} \mathrm{Cd}$ ) (Ding, et al., 2013). The difference in the results may be attributed to the use of different crops and the crop growth conditions. For both the $\mathrm{CK}$ and Cd treatments, the HMR potato variety accumulated the least $\mathrm{Cd}$ while the CA5e variety accumulated the most. In a previous study, three potato cultivars that easily uptake $\mathrm{Cd}$ from the soil, known as $\mathrm{Cd}$ accumulators, were identified from 10 cultivars based on the BAF and plant $\mathrm{Cd}$ concentration (Ashrafzadeh, et al., 2017). These studies demonstrate that identifying crop genotypes with low or high Cd accumulation based on the enrichment factor is an effective method to avoid $\mathrm{Cd}$ pollution in food.

The $\mathrm{BAF}_{\text {add }}$ of $\mathrm{Cd}$ for the 10 potato varieties evaluated in this study ranged from 0.04 (HMR) to 0.19 (CA5e), and the average $\mathrm{BAF}_{\text {add }}$ was 0.13 , which was slightly less than the average $\mathrm{BAF}_{\text {total }}$ and $\mathrm{BAF}_{\mathrm{ck}}$. The $\mathrm{BAF}_{\text {total }}$ and $\mathrm{BAF}_{\mathrm{ck}}$ indicated that the CA5e potato variety could easily uptake soil $\mathrm{Cd}$, while the HMR and HBS varieties absorbed less $\mathrm{Cd}$ from the soil. A prediction model was established based on soil Cd content, plant Cd content and soil properties ( $\mathrm{pH}$ and organic carbon) and the results showed that the $\mathrm{BAF}_{\text {total }}$ and $\mathrm{BAF}_{\mathrm{add}}$ can be used to develop a prediction 

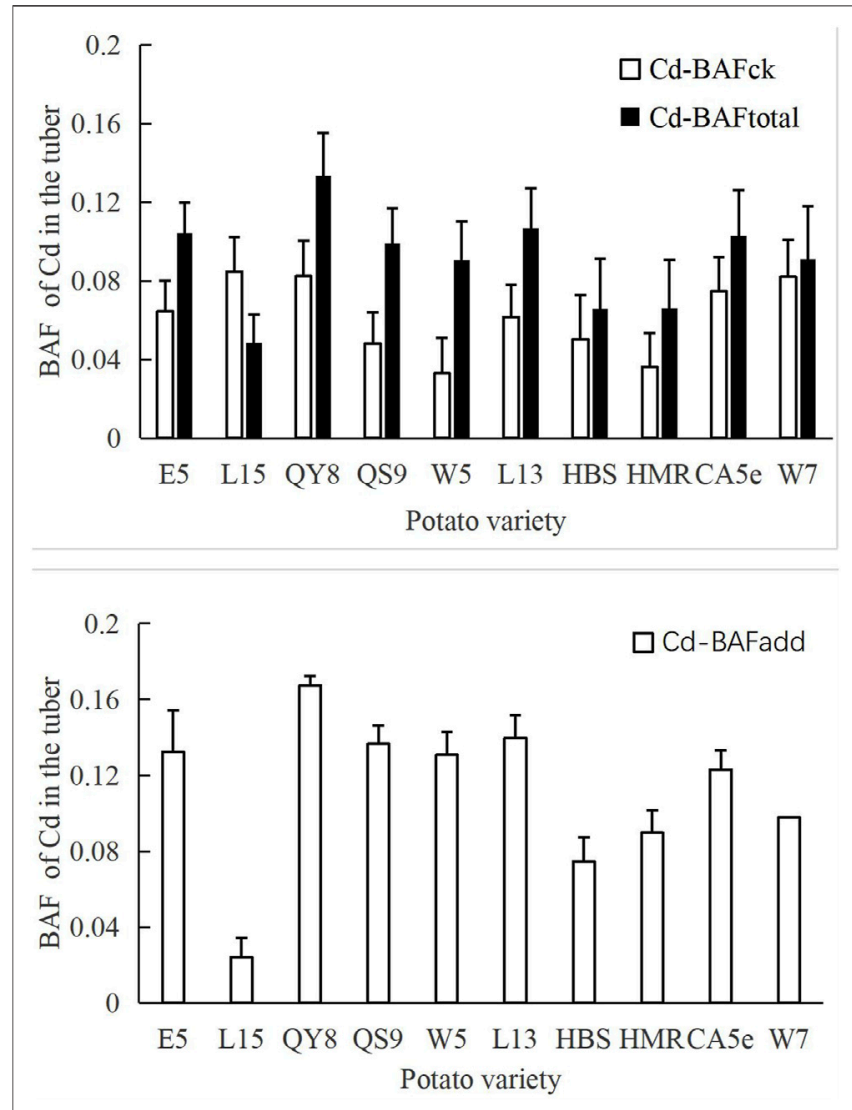

FIGURE 2 | $\mathrm{BAF}_{\mathrm{ck}}, \mathrm{BAF}_{\text {total }}$ and $\mathrm{BAF}_{\text {add }}$ for different potato varieties in Guiyang soil.

model for Cd transfer from the soil to vegetables as well as for identifying soil thresholds for food safety (Liang, et al., 2013). Empirical soil-carrot transfer models were developed for 21 soil types in China and the prediction model for added Cd was found to be better than the model for total Cd $\left(R^{2}: 0.77>0.73\right)$ (Ding, et al., 2013). These results indicated that $\mathrm{BAF}_{\text {total }}$ and $\mathrm{BAF}_{\mathrm{add}}$ are both valuable parameters for studying soil Cd uptake in crops and calculating the soil threshold.

The Cd-BAF of tuber grown in Guiyang soil ranged from 0.03 (W5) to 0.08 (L15) for $\mathrm{BAF}_{\mathrm{ck}}$ and from 0.05 (L15) to 0.13 (QY8) for $\mathrm{BAF}_{\text {total }}$. The average $\mathrm{BAF}_{\mathrm{ck}}$ and $\mathrm{BAF}_{\text {total }}$ of the tubers were 0.06 and 0.09 for different potato varieties, respectively. Some researchers studied the accumulation of $\mathrm{Cd}$ in potato with different soil Cd levels (soil $\mathrm{Cd}<25 \mathrm{mg} \mathrm{kg}^{-1}$ ) and found that the $\mathrm{BAF}_{\text {total }}$ of the tubers ranged from 0.20 to 0.81 . The $\mathrm{BAF}_{\text {total }}$ values in these studies were larger than our results, probably due to higher $\mathrm{Cd}$ pollution $\left(<25 \mathrm{mg} \mathrm{kg}^{-1}\right)$ and low $\mathrm{OM}$ content $\left(14.6 \mathrm{~g} \mathrm{~kg}^{-1}\right)$ in the soil compared to our soil conditions (soil Cd: $0.9 \mathrm{mg} \mathrm{kg}^{-1}$, OM: $48 \mathrm{~g} \mathrm{~kg}^{-1}$ ) (Chen, et al., 2014). Most of the $\mathrm{BAF}_{\text {total }}$ values were higher than the $\mathrm{BAF}_{\mathrm{ck}}$ values for specific varieties in the alkaline Guiyang soil and the opposite results were obtained in the acidic Weining soil. The biggest difference between the $\mathrm{BAF}_{\mathrm{ck}}$ and $\mathrm{BAF}_{\text {total }}$ was found in the W5 variety, which had a $\mathrm{BAF}_{\text {total }}$ value that was 2.74 times greater than the
TABLE 1 | RMSE of soil Cd threshold calculated with two functions.

\begin{tabular}{llll}
\hline \multirow{2}{*}{ Soil } & Treatment & \multicolumn{2}{c}{ Function } \\
\cline { 3 - 4 } & & Log-normal & Burr III \\
\hline \multirow{2}{*}{ Weining } & $\mathrm{BAF}_{\mathrm{ck}}$ & 0.0036 & 0.0029 \\
& $\mathrm{BAF}_{\text {total }}$ & 0.0075 & 0.0060 \\
Guiyang & $\mathrm{BAF}_{\text {add }}$ & 0.0157 & 0.0162 \\
& $\mathrm{BAF}_{\mathrm{ck}}$ & 0.0219 & 0.0283 \\
& $\mathrm{BAF}_{\text {total }}$ & 0.0104 & 0.0066 \\
& $\mathrm{BAF}_{\text {add }}$ & 0.2321 & 0.4679
\end{tabular}

Soil Cd threshold in two soil types.

TABLE 2 | Soil Cd threshold calculated with two functions for two soil types

\begin{tabular}{llcc}
\hline \multirow{2}{*}{ Soil } & Treatment & \multicolumn{2}{c}{ Function } \\
\cline { 3 - 4 } & & Log-normal & Burr III \\
\hline \multirow{2}{*}{ Weining } & BAF $_{\mathrm{ck}}$ & 0.231 & 0.284 \\
& $\mathrm{BAF}_{\text {total }}$ & 0.322 & 0.394 \\
& $\mathrm{BAF}_{\mathrm{add}}$ & $0.486+\mathrm{C}_{\mathrm{b}}$ & $0.511+\mathrm{C}_{\mathrm{b}}$ \\
& average & 0.411 & 0.461 \\
Guiyang & $\mathrm{BAF}$ & 0.937 & 1.108 \\
& $\mathrm{BAF}_{\text {total }}$ & 0.680 & 0.783 \\
& BAF & $0.337+\mathrm{C}_{\mathrm{b}}$ & $0.580+\mathrm{C}_{\mathrm{b}}$ \\
& average & 0.716 & 0.888
\end{tabular}

$B A F_{a d d}$ only considers the effect of exogenous Cd addition. The field base value of $\mathrm{Cd}$ was added to the soil threshold, and $C_{b}$ was $0.194 \mathrm{mg} / \mathrm{kg}$.

$\mathrm{BAF}_{\mathrm{ck}}$. The $\mathrm{BAF}_{\mathrm{add}}$ ranged from 0.02 (L15) to 0.17 (QY8), with an average $\mathrm{BAF}_{\mathrm{add}}$ of 0.11 , which was close to the $\mathrm{BAF}_{\text {total }}$ for the $\mathrm{Cd}$ treatments.

The transfer of $\mathrm{Cd}$ from the soil to the potato tubers was limited with the HMR and HBS varieties in both the Weining soil and Guiyang soil for the CK and Cd treatments. The QY8 and CA5e varieties were sensitive to Cd uptake from the Guiyang soil, while QY8, QS9 and CA5e were sensitive to Cd uptake from the Weining soil. QY8 and CA5e were sensitive to Cd uptake with the $\mathrm{CK}$ and $\mathrm{Cd}$ treatments in the Weining and Guiyang soils, as indicated by the high $\mathrm{BAF}_{\text {total }}$ and $\mathrm{BAF}_{\mathrm{add}}$. The $\mathrm{BAF}_{\text {add }}$ and $\mathrm{BAF}_{\text {total }}$ values demonstrated that $\mathrm{Cd}$-sensitive and insensitive potato varieties were similar in the two soil types with different $\mathrm{pH}$ values and the genotype affected food safety in the polluted soils.

The $\mathrm{BAF}_{\mathrm{ck}}$ and $\mathrm{BAF}_{\text {total }}$ values in the alkaline Guiyang soil differed from those in the acidic Weining soil. Figures 1, 2 show that the ability of the potato varieties to absorb Cd in acidic soil was stronger than that in alkaline soil for both the $\mathrm{CK}$ and $\mathrm{Cd}$ treatments based on the average $\mathrm{BAF}_{\text {total }}$ and $\mathrm{BAF}_{\mathrm{ck}} \mathrm{pH}$ is an important factor that affects the adsorption, desorption, precipitation, dissolution and complexation of heavy metals in the soil and can directly or indirectly affect the retention of heavy metals in the soil. In a previous study in which the soil $\mathrm{pH}$ was increased by 0.50 units through lime addition, the uptake of Cd by rice grain decreased by $35.3 \%$ and the Cd transfer ratio increased as the soil $\mathrm{pH}$ decreased in acidic and alkaline soils (Zhu, et al., 2016). The results of the current study demonstrated that the soil type and genotype significantly affect Cd uptake by potato and so 


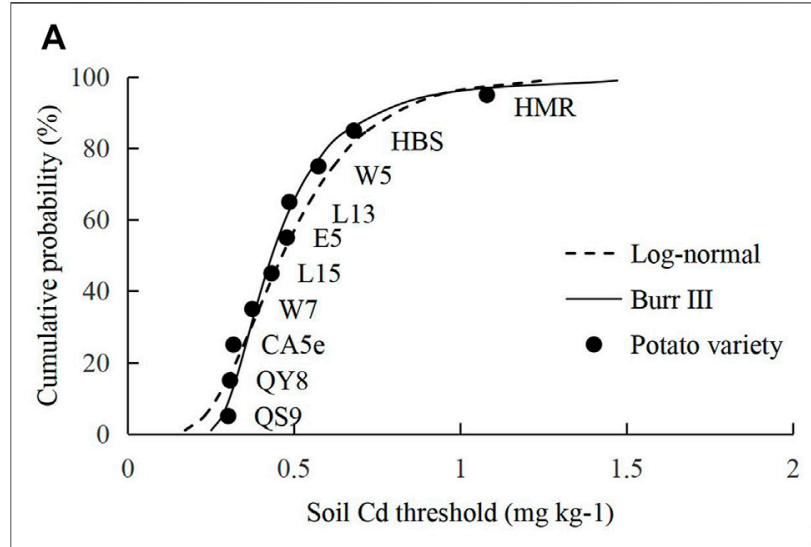

B

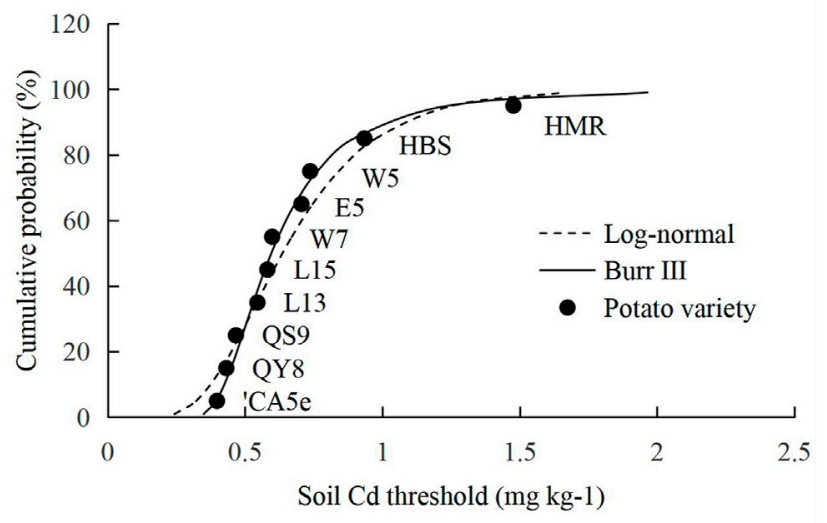

C

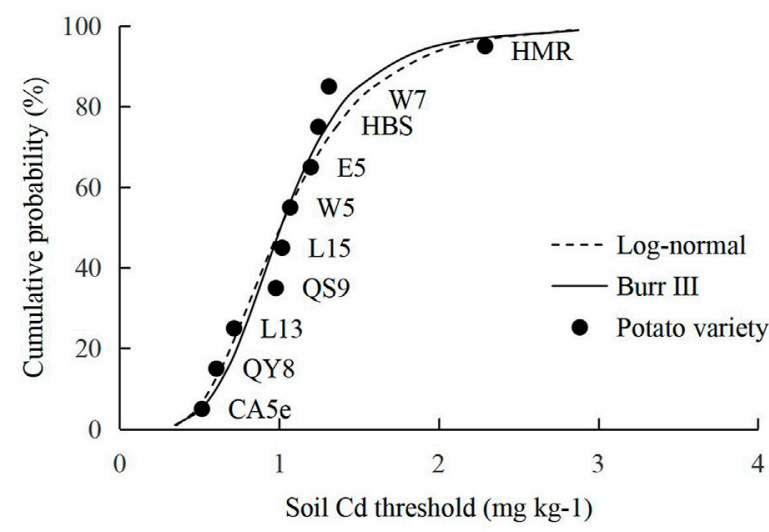

FIGURE 3 | SSD curves of different potato varieties in Weining soil. (A). $\mathrm{BAF}_{\mathrm{ck}}$, (B). BAF $\mathrm{B}_{\text {total }}, \mathbf{( C )}$. BAF $\mathrm{Bdd}_{\text {. }}$

does the interaction between these two factors. Luyin No. One was identified from four potato cultivars as a suitable cultivar for planting in slightly Cd-contaminated soils $\left(<0.6 \mathrm{mg} \mathrm{kg}^{-1}\right)$. The average reported $\mathrm{BAF}_{\mathrm{add}}$ for different cultivars is 2.3 , which is less than the reported $\mathrm{BAF}_{\text {total }}$ value (2.76) in soil with $\mathrm{pH} 6.9$ and is similar to the results for our acidic Weining soil $\left(\mathrm{BAF}_{\mathrm{add}} 0.13<\right.$ $\mathrm{BAF}_{\text {total }}$ 0.17) (Ding, et al., 2014). In general, there was significant difference between the Weining soil and Guiyang soil in both the
$\mathrm{BAF}_{\mathrm{ck}}$ and $\mathrm{BAF}_{\text {total }}$, however, $\mathrm{BAF}_{\mathrm{add}}$ was different from $\mathrm{BAF}_{\mathrm{ck}}$ and $\mathrm{BAF}_{\text {total }}$ (Table 1 in the Supplementary Data S1). The $\mathrm{BAF}_{\mathrm{ck}}, \mathrm{BAF}_{\text {total }}$ and $\mathrm{BAF}_{\mathrm{add}}$ of some varieties have significant differences, while other varieties have no significant differences among each other in the two soils, moreover, the significant difference of the $\mathrm{BAF}_{\text {total }}$ was similar to that of $\mathrm{BAF}_{\text {add }}$ (Table 2 in the Supplementary Data S1).

\section{Comparison of Log-Normal and Burr III Functions}

SSD is used to create a cumulative probability distribution curve with toxicity data that follow certain probability distributions such as the Log-normal distribution. A cumulative probability of " $p$ " indicates that (100-p)\% of organisms in the ecosystem are relatively safe in an environment containing the pollutant at the given concentration (Maltby, et al., 2009). It is worth noting that the " $\mathrm{p}$ " value is determined by the local environment safety management department rather than science, and $5 \%$ is often used as the threshold value for ecological safety. The soil Cd threshold for each potato variety was obtained based on the BAF $\left(\mathrm{C}_{\text {soil threshold }}=0.1 / \mathrm{BAF}, 0.1 \mathrm{mg} \mathrm{kg}^{-1}\right.$ is the limit for the Chinese food safety standard (GB 2762-2017); BAF can refer to $\mathrm{BAF}_{\mathrm{ck}}$, $\mathrm{BAF}_{\text {total }}$ or $\left.\mathrm{BAF}_{\mathrm{add}}\right)$. The $\mathrm{C}_{\text {soil threshold }}$ of 10 potato varieties was applied to calculated the final soil Cd threshold in order to protect 95\% potato and the value of soil $\mathrm{Cd}$ threshold was equaled to the $5 \%$ cumulative probability. The Burr III or Log-normal function was used to generate an SSD curve and a 5\% cumulative probability to protect $95 \%$ of species was set as the final soil threshold to protect most potato varieties from Cd damage. A similar method was applied to determine the Cd soil threshold for wheat in different soils using the SSD fitted with the Log-normal function (Liu, et al., 2015). The soil Cd threshold increased with the increase of the cumulative probability. When the cumulative probability was less than $30 \%$, the soil threshold calculated with the Log-normal function was less than that calculated with the Burr III function. In contrast, when the cumulative probability was greater than $30 \%$, the opposite results were obtained for the soil threshold calculated with the two functions. The $\mathrm{BAF}_{\mathrm{ck}}$ indicated that the sensitivity levels of the QS9 and HMR varieties to soil Cd were significantly different. QY8 and QS9 easily absorbed $\mathrm{Cd}$ from the soil and other potato varieties were relatively insensitive to $\mathrm{Cd}$ compared to these two varieties (Figure 3A). The $\mathrm{BAF}_{\text {total }}$ values for the potato varieties were evenly distributed on the two SSD curves. The soil Cd threshold fitted with the Log-normal function was less than that obtained with the Burr III function at a low cumulative probability $(<30 \%)$ and was similar to the $\mathrm{BAF}_{\mathrm{ck}}$. The $\mathrm{HMR}$ variety was the most insensitive to $\mathrm{Cd}$, evidenced by both the $\mathrm{BAF}_{\mathrm{ck}}$ and $\mathrm{BAF}_{\text {total }}$. The soil Cd threshold was obtained based on the $\mathrm{BAF}_{\text {total }}$ and the SSD curves fitted with the Burr III and Log-normal functions were "Sshaped" (Figure 3B). When we focused on the effect of $\mathrm{Cd}$ addition on the bioavailability of potato tubers $\left(\mathrm{BAF}_{\mathrm{add}}\right)$, we found that the CA5e potato variety was relatively sensitive to soil Cd while the HMR variety had a strong resistance to soil Cd uptake. The curves calculated with the Burr III and Log-normal functions were almost the same when the cumulative probability 

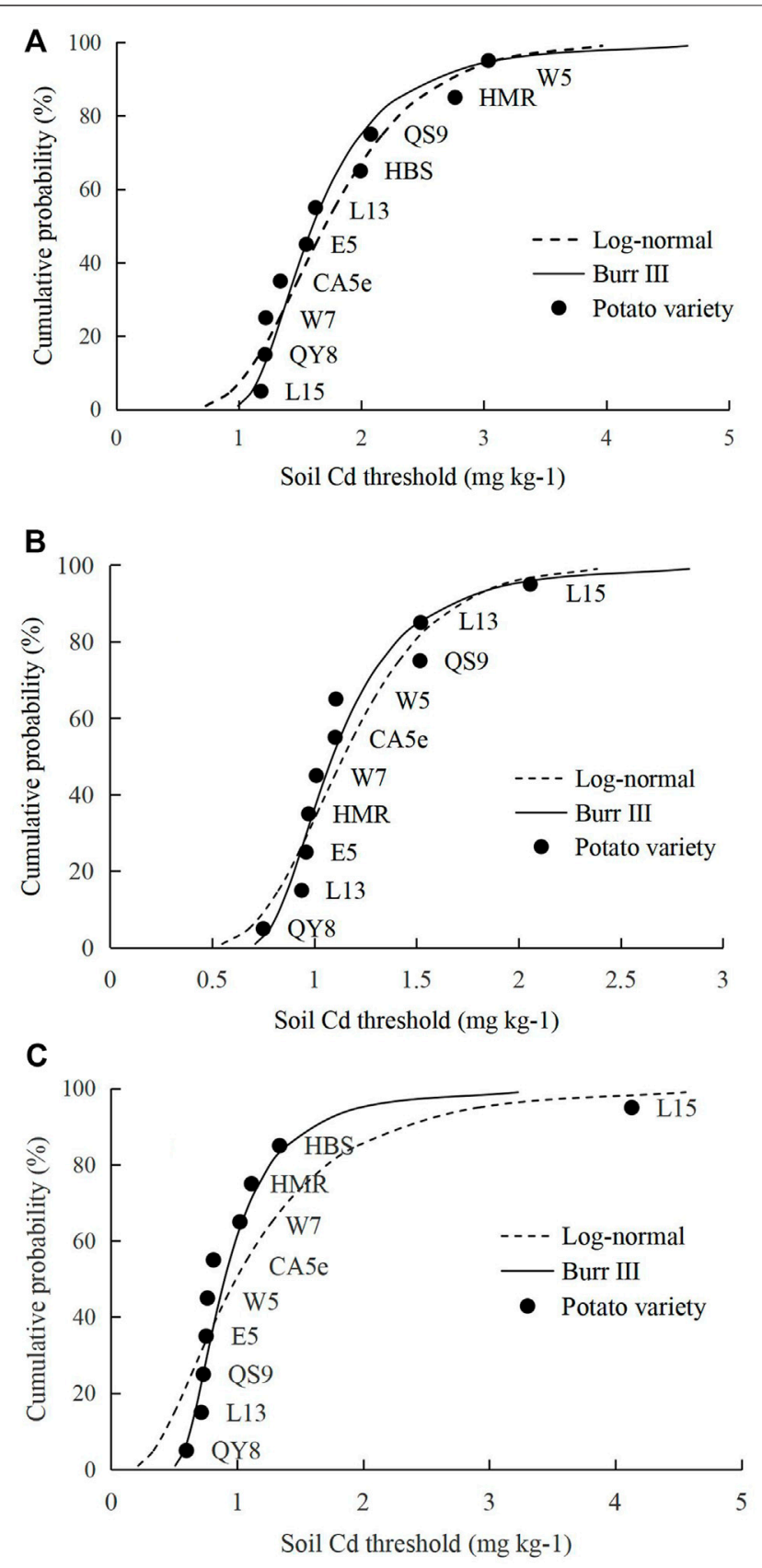

FIGURE 4 | SSD curves of different potato varieties in Guiyang soil. (A). $\mathrm{BAF}_{\mathrm{ck}}$, (B). BAF $\mathrm{B}_{\text {total }},(\mathbf{C}) . \mathrm{BAF}_{\mathrm{add}}$.

was less than 5\%; therefore, the soil Cd thresholds calculated with the two functions were relatively similar when the protection of more than $95 \%$ of potato varieties was taken into consideration (Figure 3C). Based on a combination of the $\mathrm{BAF}_{\text {total }}$ and $\mathrm{BAF}_{\mathrm{add}}$ values, the $\mathrm{CA} 5 \mathrm{e}$ and $\mathrm{HMR}$ potato varieties were the most sensitive and insensitive to soil $\mathrm{Cd}$ in Weining soil in Karst areas, respectively. The identification of Cd-resistant potato varieties is helpful for local food safety. In a study using SSD, Xiangzao 17 was identified as the most sensitive rice cultivar to soil Cd among 20 rice cultivars based on the cumulative probability distribution curve calculated with 1/BAF. The results demonstrated that the SSD method was helpful to screen sensitive and insensitive varieties for pollutants (Song, et al., 2015).

The soil threshold for Cd established with the Burr III function was higher than that calculated with the Log-normal function at a low cumulative probability, and the opposite was true for a high cumulative probability (Figures 4A,B). This result was similar to the results for the SSD curves of $\mathrm{BAF}_{\mathrm{ck}}$ and $\mathrm{BAF}_{\text {total }}$ for the Cd treatments in Weining soil. However, the SSD curve fitting for $\mathrm{BAF}_{\mathrm{add}}$ with the Burr III function was quite different from that with the Log-normal function, and unlike the SSD curve in acidic Weining soil (Figure 4C). QY8 was sensitive and L15 was insensitive to Cd uptake, as indicated by their respective curves for $\mathrm{BAF}_{\text {total }}$ and $\mathrm{BAF}_{\mathrm{add}}$. The Burr III function is considered the best function for soil $\mathrm{Cd}$ threshold calculations and has been used to determine the soil $\mathrm{Cd}$ threshold for vegetables including potato in acidic and neutral soils based on the $\mathrm{BAF}_{\text {add }}$. Cdsensitive species and hazardous concentrations within the fifth percentile, reflecting the protection of $95 \%$ of species, can also be determined using the SSD (Ding, et al., 2018). The sensitivity levels of the potato varieties were similar in the acidic Weining soil and the alkaline Guiyang soil, as indicated by the $\mathrm{BAF}_{\text {total }}$ and $\mathrm{BAF}_{\mathrm{add}}$, but differed from the sensitivity levels with $\mathrm{CK}$ treatment, as indicated by $\mathrm{BAF}_{\mathrm{ck}}$. The toxicity sensitivity of different potato varieties to the soil $\mathrm{Cd}$ can be directly observed from the SSD curves based on the $\mathrm{BAF}_{\mathrm{ck}}$, $\mathrm{BAF}_{\text {total }}$ and $\mathrm{BAF}_{\mathrm{add}}$, which reflect the transfer capacity of heavy metals.

The RMSE represents the deviation between the prediction and the measured value, and a smaller RMSE indicates better prediction accuracy. The RMSE between the predicted and measured soil $\mathrm{Cd}$ threshold values for the 10 potato varieties established with $\mathrm{BAF}_{\text {add }}$ was larger than that established with $\mathrm{BAF}_{\mathrm{ck}}$ and $\mathrm{BAF}_{\text {total }}$ in the two soil types using the two functions (Table 1). This suggested that $\mathrm{BAF}_{\text {total }}$ and $\mathrm{BAF}_{\mathrm{ck}}$ were more suitable for studying the transfer of $\mathrm{Cd}$ from the soil to plants. The predictive accuracy of the $\mathrm{BAF}_{\mathrm{ck}}$ and $\mathrm{BAF}_{\text {total }}$ values was better in Weining and Guiyang soils, respectively. The RMSE values for the Burr III function with the $\mathrm{BAF}_{\mathrm{ck}}$ and $\mathrm{BAF}_{\text {total }}$ values were less than those for the Log-normal function in acidic Weining soil, indicating that the Burr III function was better suited for determining the soil $\mathrm{Cd}$ threshold for this soil type. Lognormal was more appropriate for $\mathrm{BAF}_{\mathrm{add}}$ and $\mathrm{BAF}_{\mathrm{ck}}$ in alkaline Guiyang soil. The high prediction accuracy of the soil threshold for $\mathrm{BAF}_{\mathrm{ck}}, \mathrm{BAF}_{\text {total }}$ and $\mathrm{BAF}_{\mathrm{add}}$ confirmed that the Burr III and Log-normal functions can both be applied to obtain the soil Cd threshold. However, the optimal function needs to be selected depending on the soil type and BAF calculation method. $\mathrm{BAF}_{\text {add }}$ was reported to be better for the determination of the soil $\mathrm{Cd}$ threshold for the safe production of rice in paddy soils $(\mathrm{pH}$ : 4.94-6.72) and the Burr III function is commonly used to fit SSD curves (Li L et al., 2021). The results of these studies are different from ours, in which $\mathrm{BAF}_{\text {total }}$ was better than $\mathrm{BAF}_{\mathrm{add}}$, probably due to different experimental conditions and species. 
As shown in Table 2, the soil Cd threshold for the Weining soil calculated with the Log-normal function was a little less than that calculated with the Burr III function using the $\mathrm{BAF}_{\mathrm{ck}}, \mathrm{BAF}_{\text {total }}$ and $\mathrm{BAF}_{\text {add }}$ values. The soil Cd threshold obtained with $\mathrm{BAF}_{\text {add }}$ was higher than those obtained with $\mathrm{BAF}_{\mathrm{ck}}$ and $\mathrm{BAF}_{\text {total }}$. The average soil Cd threshold was slightly higher than the Chinese national soil standard for $\mathrm{Cd}\left(0.3 \mathrm{mg} \mathrm{kg}^{-1}\right)$. Similarly, the soil Cd threshold in Guiyang soil calculated with the Burr III function was higher than that calculated with the Log-normal function and was slightly higher than the Chinese soil screening value for agriculture $\left(0.6 \mathrm{mg} \mathrm{kg}^{-1}\right)$. The soil $\mathrm{Cd}$ threshold for $\mathrm{BAF}_{\mathrm{add}}$ was lower than those for $\mathrm{BAF}_{\mathrm{ck}}$ and $\mathrm{BAF}_{\text {total }}$. These findings differed from the results obtained for Weining soil. Some researchers have applied similar methods to determine the soil threshold for other pollutants. The soil $\mathrm{Pb}$ threshold was obtained for 12 root vegetable cultivars based on the SSD and the threshold values based on $\mathrm{BAF}_{\mathrm{add}}$ were lower than the standard for $\mathrm{Pb}$ in the soil (Ding, et al., 2016). Risk evaluation of Cd in soil-rice systems ( $n=124)$ was conducted using SSD curves from rice Cd-BAF $F_{\text {total }}$ in Hunan Province, China (Yang et al., 2016b). The soil Cd threshold obtained in this study is conducive to the protection of local potatoes from $\mathrm{Cd}$ pollution, the evaluation of $\mathrm{Cd}$ pollution and the development of soil quality guidelines.

\section{CONCLUSION}

The BAF values for different potato varieties in acidic soil were higher than those in alkaline soil for the CK and Cd treatments. The HMR and CA5e potato varieties were quite insensitive and sensitive in acidic soil, whereas QY8 and L15 were sensitive and insensitive in alkaline soil.

The soil Cd threshold values obtained with the Log-normal function using $\mathrm{BAF}_{\mathrm{ck}}, \mathrm{BAF}_{\text {total }}$ and $\mathrm{BAF}_{\mathrm{add}}$ were less than those obtained with the Burr III function in the Weining and Guiyang soils. The soil $\mathrm{Cd}$ threshold values were in the order $\mathrm{BAF}_{\mathrm{add}}>$ $\mathrm{BAF}_{\text {total }}>\mathrm{BAF}_{\mathrm{ck}}$ in Weining soil for the Log-normal and Burr III

\section{REFERENCES}

Ashrafzadeh, S., Gaw, S., Genet, R., Glover, C. N., and Leung, D. W. M. (2017). Natural Variation in Correlations between Cadmium and Micronutrients in Potato Tubers. J. Food Compost. Anal. 59, 55-60. doi:10.1016/j.jfca.2017.02.008

Augustsson, A. L. M., Uddh-Söderberg, T. E., Hogmalm, K. J., and Filipsson, M. E. M. (2015). Metal Uptake by Homegrown Vegetables - the Relative Importance in Human Health Risk Assessments at Contaminated Sites. Environ. Res. 138, 181-190. doi:10.1016/j.envres.2015.01.020

Carvalho, M. E. A., Piotto, F. A., Gaziola, S. A., Jacomino, A. P., Jozefczak, M., and Cuypers, A. etal. (2018). New Insights about Cadmium Impacts on Tomato: Plant Acclimation, Nutritional Changes, Fruit Quality and Yield. Food Energy. Secur. 7. doi:10.1002/fes3.131

Chen, Z., Zhao, Y., Gu, L., Wang, S., Li, Y., and Dong, F. (2014). Accumulation and Localization of Cadmium in Potato (Solanum tuberosum) under Different Soil Cd Levels. Bull. Environ. Contam. Toxicol. 92, 745-751. doi:10.1007/s00128014-1252-3

Ding, C., Ma, Y., Li, X., Zhang, T., and Wang, X. (2016). Derivation of Soil Thresholds for lead Applying Species Sensitivity Distribution: A Case Study for Root Vegetables. J. Hazard. Mater. 303, 21-27. doi:10.1016/j.jhazmat.2015. 10.027 functions. The soil Cd threshold values were in the order $\mathrm{BAF}_{\mathrm{ck}}>$ $\mathrm{BAF}_{\text {total }}>\mathrm{BAF}_{\text {add }}$ for the Guiyang soil. The RMSE for $\mathrm{BAF}_{\text {total }}$ was less than that for $\mathrm{BAF}_{\mathrm{add}}$ based on the two functions in the Weining and Guiyang soils, indicating that $\mathrm{BAF}_{\text {total }}$ was more appropriate for calculating the soil threshold of $\mathrm{Cd}$ compared to $\mathrm{BAF}_{\mathrm{add}}$.

\section{DATA AVAILABILITY STATEMENT}

The original contributions presented in the study are included in the article/Supplementary Material, further inquiries can be directed to the corresponding author.

\section{AUTHOR CONTRIBUTIONS}

WL: Writing-original draft preparation, Investigation and formal analysis. XH: Investigation, Writing and Editing. JZ: Experimental formal analysis and software analysis. KL: Methodology, Writing_-review and editing, Formal analysis.

\section{FUNDING}

This research was supported by the National Natural Science Foundation of China (21866008) and the Science and Technology Planning Project of Guizhou Province, China (Qiankehejichu no (2019)1103, Qiankehehoubuzu no. (2020)3001).

\section{SUPPLEMENTARY MATERIAL}

The Supplementary Material for this article can be found online at: https://www.frontiersin.org/articles/10.3389/fenvs.2022.808362/ full\#supplementary-material

Ding, C., Ma, Y., Li, X., Zhang, T., and Wang, X. (2018). Determination and Validation of Soil Thresholds for Cadmium Based on Food Quality Standard and Health Risk Assessment. Sci. Total Environ. 619-620, 700-706. doi:10.1016/ j.scitotenv.2017.11.137

Ding, C., Zhang, T., Wang, X., Zhou, F., Yang, Y., and Huang, G. (2013). Prediction Model for Cadmium Transfer from Soil to Carrot (Daucus Carota L.) and its Application to Derive Soil Thresholds for Food Safety. J. Agric. Food Chem. 61, 10273-10282. doi:10.1021/jf4029859

Ding, C., Zhang, T., Wang, X., Zhou, F., Yang, Y., and Yin, Y. (2014). Effects of Soil Type and Genotype on Cadmium Accumulation by Rootstalk Crops: Implications for Phytomanagement. Int. J. Phytoremediation 16, 1018-1030. doi:10.1080/15226514.2013.810581

Hough, R. L., Breward, N., Young, S. D., Crout, N. M. J., Tye, A. M., au, A. M., et al. (2004). Assessing Potential Risk of Heavy Metal Exposure from Consumption of home-produced Vegetables by Urban Populations. Environ. Health Perspect. 112, 215-221. doi:10.1289/ehp.5589

Hu, W., Huang, B., Borggaard, O. K., Ye, M., Tian, K., au, H., et al. (2018). Soil Threshold Values for Cadmium Based on Paired Soil-Vegetable Content Analyses of Greenhouse Vegetable Production Systems in China: Implications for Safe Food Production. Environ. Pollut. 241, 922-929. doi:10.1016/j.envpol.2018.06.034 
Li, D., Chen, H., Liu, H., Schlenk, D., Mu, J., au, S., et al. (2021). Anticancer Drugs in the Aquatic Ecosystem: Environmental Occurrence, Ecotoxicological Effect and Risk Assessment. Environ. Int. 153, 106543. doi:10.1016/j.envint.2021. 106543

Li, K., Cao, C., Ma, Y., Su, D., and Li, J. (2019). Identification of Cadmium Bioaccumulation in rice (Oryza Sativa L.) by the Soil-Plant Transfer Model and Species Sensitivity Distribution. Sci. Total Environ. 692, 1022-1028. doi:10. 1016/j.scitotenv.2019.07.091

Li, L., Jiang, B., Wan, Y., Li, J., and Ma, Y. (2021). Integrating Bioavailability and Aging in the Criteria Derivation of Cadmium for the Safe Production of rice in Paddy Soils. Ecotox. Environ. Safe. 219. doi:10.1016/j.ecoenv. 2021.112356

Liang, Z., Ding, Q., Wei, D., Li, J., Chen, S., and Ma, Y. (2013). Major Controlling Factors and Predictions for Cadmium Transfer from the Soil into Spinach Plants. Ecotoxicology Environ. Saf. 93, 180-185. doi:10.1016/j.ecoenv.2013. 04.003

Liu, K., Lv, J., Dai, Y., Zhang, H., and Cao, Y. (2016). Cross-Species Extrapolation of Models for Predicting lead Transfer from Soil to Wheat Grain. PLoS One 11, e0160552. doi:10.1371/journal.pone.0160552

Liu, K., Lv, J., He, W., Zhang, H., Cao, Y., and Dai, Y. (2015). Major Factors Influencing Cadmium Uptake from the Soil into Wheat Plants. Ecotoxicology Environ. Saf. 113, 207-213. doi:10.1016/j.ecoenv.2014.12.005

Maltby, L., Brock, T. C. M., and van den Brink, P. J. (2009). Fungicide Risk Assessment for Aquatic Ecosystems: Importance of Interspecific Variation, Toxic Mode of Action, and Exposure Regime. Environ. Sci. Technol. 43, 7556-7563. doi:10.1021/es901461c

Novotná, M., Mikeš, O., and Komprdová, K. (2015). Development and Comparison of Regression Models for the Uptake of Metals into Various Field Crops. Environ. Pollut. 207, 357-364. doi:10.1016/j.envpol.2015.09.043

Pinto, E., Almeida, A. A., and Ferreira, I. M. P. L. V. O. (2015). Assessment of Metal(loid)s Phytoavailability in Intensive Agricultural Soils by the Application of Single Extractions to Rhizosphere Soil. Ecotoxicology Environ. Saf. 113, 418-424. doi:10.1016/j.ecoenv.2014.12.026

Song, W.-e., Chen, S.-b., Liu, J.-f., Chen, L., Song, N.-n., au, N., et al. (2015). Variation of Cd Concentration in Various rice Cultivars and Derivation of Cadmium Toxicity Thresholds for Paddy Soil by Species-Sensitivity Distribution. J. Integr. Agric. 14, 1845-1854. doi:10.1016/s2095-3119(14) 60926-6

van der Hoeven, N. (2001). Estimating the 5-percentile of the Species Sensitivity Distributions without Any Assumptions about the Distribution. Ecotoxicology (London, England) 10, 25-34. doi:10.1023/a:1008998405241
Yang, Y., Chen, W. P., Li, Y. L., Wang, M. E., and Peng, C. (2016a). Comprehensive Risk Evaluation of Cadmium in Soil-rice System Based on Uncertainty Analysis. Huan jing ke xue 37, 4800-4805. doi:10.13227/j.hjkx.201606073

Yang, Y., Chen, W., Wang, M., and Peng, C. (2016b). Regional Accumulation Characteristics of Cadmium in Vegetables: Influencing Factors, Transfer Model and Indication of Soil Threshold Content. Environ. Pollut. 219, 1036-1043. doi:10.1016/j.envpol.2016.09.003

Ye, Y., Dong, W., Luo, Y., Fan, T., Xiong, X., au, L., et al. (2020). Cultivar Diversity and Organ Differences of Cadmium Accumulation in Potato (Solanum tuberosum L.) Allow the Potential for Cd-Safe Staple Food Production on Contaminated Soils. Sci. Total Environ. 711, 134534. doi:10.1016/j.scitotenv. 2019.134534

Zhang, Z., Wu, X., Tu, C., Huang, X., Zhang, J., au, H., et al. (2020). Relationships between Soil Properties and the Accumulation of Heavy Metals in Different Brassica Campestris L. Growth Stages in a Karst Mountainous Area. Ecotoxicol Environ. Saf. 206, 111150. doi:10.1016/j.ecoenv.2020.111150

Zhong, M.-S., Jiang, L., Han, D., Xia, T.-X., Yao, J.-J., au, X.-Y., et al. (2015) Cadmium Exposure via Diet and its Implication on the Derivation of HealthBased Soil Screening Values in China. J. Expo. Sci. Environ. Epidemiol. 25, 433-442. doi:10.1038/jes.2015.5

Zhu, H., Chen, C., Xu, C., Zhu, Q., and Huang, D. (2016). Effects of Soil Acidification and Liming on the Phytoavailability of Cadmium in Paddy Soils of central Subtropical China. Environ. Pollut. 219, 99-106. doi:10.1016/ j.envpol.2016.10.043

Conflict of Interest: The authors declare that the research was conducted in the absence of any commercial or financial relationships that could be construed as a potential conflict of interest.

Publisher's Note: All claims expressed in this article are solely those of the authors and do not necessarily represent those of their affiliated organizations, or those of the publisher, the editors and the reviewers. Any product that may be evaluated in this article, or claim that may be made by its manufacturer, is not guaranteed or endorsed by the publisher.

Copyright (C) $2022 \mathrm{Li}, \mathrm{He}$, Zhang and Liu. This is an open-access article distributed under the terms of the Creative Commons Attribution License (CC BY). The use, distribution or reproduction in other forums is permitted, provided the original author(s) and the copyright owner(s) are credited and that the original publication in this journal is cited, in accordance with accepted academic practice. No use, distribution or reproduction is permitted which does not comply with these terms. 